\title{
Analysis of ethnic influence on stillbirths and infant mortality in Bradford 1975-81
}

\author{
DOUGLAS R N GiLlies, GEOFFREY T LEALMAN, KATHLEEN M LUMB, AND \\ PETER CONGDON
}

From the Ethnic Minorities Health Studies Centre, Bradford Royal Infirmary, Bradford 8, UK

SUMMARY The patterns of mortality from birth to 1 year in Bradford were studied in the seven year period 1975-81. Large differences in mortality between the Asian and non-Asian population were shown. In $198177 \%$ of Bradford Asian families were of Pakistani origin, the remaining $23 \%$ consisting of families from other parts of the Indian subcontinent and a few from East Africa. There was excess mortality with associated congenital abnormality in the Asian population. From 1975 to 1981 there were 133 deaths associated with congenital abnormality (a rate of 12.4 per 1000 total births) in the Asian population compared with a figure of 129 (4.8 per 1000) in the non-Asian population. The differences between the two groups are shown to be largely independent of social class, and other possible reasons for the discrepancy between the Asian and non-Asian populations are discussed.

Asian births in Bradford rose from $22 \%$ of the total births in 1975 to $30.5 \%$ in 1981 . This retrospective study examines the stillbirth and infant mortality rates in Bradford and compares the Asian with the non-Asian community. Considerable differences in mortality rates are shown and reasons to account for this are discussed. In addition deaths with associated congenital abnormality are examined in more detail.

\section{Methods}

Unlike some other hospital based studies ${ }^{2}$ these data are derived from all births and infant deaths occurring within a health district. In Bradford $99 \%$ of births take place in the city's two maternity units. Basic data such as maternal parity and infant weight are stored on computer and are easily retrievable, but we obtained more detailed information from maternal and neonatal notes, hospital and coroners' necropsies, and death certificates. In addition stillbirths and neonatal deaths are discussed at bimonthly perinatal mortality meetings.

Mortality patterns were looked at in three groups:

(a) Stillbirths.

(b) Early neonatal deaths at under 1 week.

(c) Infant deaths from 1 week to 1 year.

Rates and patterns of congenital abnormality were also studied within these three groups.

\section{Results}

Table 1 shows the consistently higher level of mortality in the Asian population that is reflected in the increased stillbirth rate and persists till the end of the first year. Mortality rates tended to drop in both groups over the seven year study period, but even in 1981 the perinatal mortality rate for the Asian community was double that for the Caucasian community at $20 \cdot 8 / 1000$ total births.

To see whether congenital abnormality contributed to these differing rates, patterns of congenital abnormality were analysed and are shown in table 2 . The years $1975-81$ are grouped together as numbers are otherwise inadequate. Analysis showed similar patterns each year to that shown overall. Congenital abnormality is a serious problem in the Asian population, being twice as common in stillbirths at $4 \cdot 6 / 1000$ total births as against $2 \cdot 1 / 1000$ total births for non-Asians. The high mortality due to congenital abnormality persists throughout the first year. By the end of the first year deaths from congenital abnormality account for $12 \cdot 8 / 1000$ total births in Asians (133 babies) and 4.8/1000 total births in non-Asians (129 babies) $(\mathrm{p}<0.0001)$.

The Pakistani community is the predominant Asian group in Bradford and had $74 \%$ of all deaths associated with congenital abnormality that we were able to analyse (table 3 ). In $11 \%$ of Asian deaths we 
Table 1 Mortality rates $1975-81$

\begin{tabular}{|c|c|c|c|c|c|c|c|c|}
\hline & \multicolumn{2}{|c|}{$\begin{array}{l}\text { Stillbirths per } \\
1000 \text { total births }\end{array}$} & \multicolumn{2}{|c|}{$\begin{array}{l}\text { Early neonatal deaths per } \\
1000 \text { live births }\end{array}$} & \multicolumn{2}{|c|}{$\begin{array}{l}\text { Perinatal mortality per } \\
1000 \text { total births }\end{array}$} & \multicolumn{2}{|c|}{$\begin{array}{l}\text { Infant mortality rate per } \\
1000 \text { births }\end{array}$} \\
\hline & Asian & Non-Asian & Asian & Non-Asian & Asian & Non-Asian & Asian & Non-Asian \\
\hline $\begin{array}{l}1975 \\
1976 \\
1977 \\
1978 \\
1979 \\
1980 \\
1981 \\
1975-81 \text { inclusive }\end{array}$ & $\begin{array}{l}18 \cdot 5 \\
19 \cdot 0 \\
19 \cdot 1 \\
11 \cdot 0 \\
11 \cdot 5 \\
18 \cdot 3 \\
13 \cdot 5 \\
15 \cdot 5\end{array}$ & $\begin{array}{r}11 \cdot 2 \\
11 \cdot 5 \\
7 \cdot 8 \\
9 \cdot 1 \\
9 \cdot 7 \\
5 \cdot 7 \\
5 \cdot 9 \\
8 \cdot 7\end{array}$ & $\begin{array}{r}11 \cdot 3 \\
14 \cdot 0 \\
12 \cdot 2 \\
9 \cdot 1 \\
10 \cdot 5 \\
11 \cdot 2 \\
7 \cdot 4 \\
10 \cdot 6\end{array}$ & $\begin{array}{l}8 \cdot 9 \\
7 \cdot 9 \\
7 \cdot 3 \\
7 \cdot 3 \\
7 \cdot 0 \\
3 \cdot 7 \\
3 \cdot 7 \\
6 \cdot 5\end{array}$ & $\begin{array}{l}26 \cdot 9 \\
32 \cdot 8 \\
31 \cdot 1 \\
20 \cdot 0 \\
21 \cdot 8 \\
29 \cdot 2 \\
20 \cdot 8 \\
25 \cdot 9\end{array}$ & $\begin{array}{r}19 \cdot 9 \\
19 \cdot 3 \\
15 \cdot 0 \\
16 \cdot 3 \\
16 \cdot 6 \\
9 \cdot 4 \\
9 \cdot 7 \\
15 \cdot 1\end{array}$ & $\begin{array}{l}22 \cdot 6 \\
27 \cdot 2 \\
23 \cdot 0 \\
20 \cdot 2 \\
19 \cdot 7 \\
22 \cdot 9 \\
17 \cdot 1 \\
21 \cdot 6\end{array}$ & $\begin{array}{r}15 \cdot 6 \\
14 \cdot 8 \\
16 \cdot 4 \\
17 \cdot 3 \\
14 \cdot 4 \\
12 \cdot 4 \\
9 \cdot 0 \\
14 \cdot 1\end{array}$ \\
\hline Total No & 165 & 232 & 111 & 172 & 276 & 404 & 226 & 376 \\
\hline
\end{tabular}

Total births: Asian 10647 , non-Asian 26834.

Table 2 Mortality associated with congenital abnormality 1975-81 inclusive

\begin{tabular}{|c|c|c|c|c|c|c|c|c|c|c|c|c|}
\hline & \multicolumn{4}{|c|}{ Stillbirths } & \multicolumn{4}{|c|}{ Early neonatal deaths } & \multicolumn{4}{|c|}{ Deaths 1 week-1 year } \\
\hline & \multicolumn{2}{|c|}{ Asian } & \multicolumn{2}{|c|}{ Non-Asian } & \multicolumn{2}{|c|}{ Asian } & \multicolumn{2}{|c|}{ Non-Asian } & \multicolumn{2}{|c|}{ Asian } & \multicolumn{2}{|c|}{ Non-Asian } \\
\hline & No & Rate & No & Rate & No & Rate & No & Rate & No & Rate & No & Rate \\
\hline $\begin{array}{l}\text { Congenital abnormality: } \\
\text { Central nervous system }\end{array}$ & & & & 1.7 & 3 & 0.3 & 7 & 0.3 & 15 & 1.4 & 10 & 0.4 \\
\hline Cardiovascular system & - & - & - & - & 12 & $1 \cdot 1$ & 7 & $0 \cdot 3$ & - & - & - & - \\
\hline Renal & 1 & - & - & - & 7 & 0.7 & 3 & $0 \cdot 1$ & - & - & - & - \\
\hline $\begin{array}{l}\text { Others including multiple } \\
\text { congenital abnormality } \\
\text { Total } \\
\text { Total of all deaths }\end{array}$ & $\begin{array}{r}13 \\
49 \\
165\end{array}$ & $\begin{array}{r}1 \cdot 2 \\
4 \cdot 6 \\
15 \cdot 5\end{array}$ & $\begin{array}{r}9 \\
56 \\
232\end{array}$ & $\begin{array}{l}0 \cdot 3 \\
2 \cdot 1 \\
8 \cdot 7\end{array}$ & $\begin{array}{r}21 \\
43 \\
111\end{array}$ & $\begin{array}{r}2 \cdot 0 \\
4 \cdot 1 \\
10 \cdot 6\end{array}$ & $\begin{array}{r}12 \\
29 \\
172\end{array}$ & $\begin{array}{l}0 \cdot 4 \\
1 \cdot 1 \\
6 \cdot 5\end{array}$ & $\begin{array}{r}26 \\
41 \\
116\end{array}$ & $\begin{array}{r}2 \cdot 5 \\
3 \cdot 9 \\
11 \cdot 1\end{array}$ & $\begin{array}{r}34 \\
44 \\
201\end{array}$ & $\begin{array}{l}1 \cdot 3 \\
1 \cdot 7 \\
7 \cdot 6\end{array}$ \\
\hline
\end{tabular}

Table 3 Asian deaths associated with congenital abnormality: analysis by ethnic group (stillbirths and infant deaths 1975-81 inclusive)

\begin{tabular}{lr}
\hline Pakistani & 98 \\
Indian & 19 \\
Bangladeshi & 1 \\
Asian subgroup unknown & 15 \\
\hline
\end{tabular}

were unable to classify the Asian subgroup. Therefore, most observations made regarding the Bradford Asians apply to the Pakistani population which suffers severe social disadvantages when compared with the non-Asian population. ${ }^{3}$

To compensate for this social class difference table 4 shows class specific death rates. The analysis was made for the years $1979-81$ as earlier data were not available. It is striking that in social clases IV and V deaths associated with congenital abnormality are significantly greater $(p<0.01)$ at $20.0 / 1000$ total births in the Asian population. Deaths not associated with congenital abnormality showed similar rates in both groups.

\section{Discussion}

Rates for stillbirths and deaths under the age of 1 year were throughout higher in the Asian population. These high mortality rates have been seen in previous studies of immigrant groups, but this paper illustrates the large burden of congenital abnormality borne by the Asian population in this area. With regard to stillbirths, malformations of the central nervous system are the most common congenital abnormality in both groups but the incidence of this in the Asian population, $3 \cdot 3 / 1000$ total births (35 babies), is almost double that in the non-Asian population $(1 \cdot 4 / 1000)$. Nevertheless, all types of congenital abnormality are more common in the Asian population, and in particular we show that multiple congenital abnormality is much more frequent with many of the patterns of abnormality being unrecognisable as specific syndromes. Although many congenital abnormalities are lethal either at birth or within one week of birth, there remains a high level of deaths associated with congenital abnormality in the period 1 week to 1 year. During this period $35 \%$ of deaths in the Asian population (41 babies) are associated with congenital abnormality as compared with $22 \%$ in the non-Asian population (44 babies).

Several factors might be operating in the Asian community to produce the high of mortality and 
congenital abnormality. Perinatal mortality is closely linked to social class. ${ }^{4}$ In the years $1979-81$ inclusive $70 \%$ of Asian mothers came from social classes IV and $\mathrm{V}$ compared with $23.2 \%$ of non-Asians. Other associated factors favouring high mortality rates in the Asian population are low maternal height, poor antenatal attendance, generally lower concentrations of haemoglobin during pregnancy, the high parity of Asian mothers, the practice of child bearing till late in life, and the high numbers of low birthweight babies. ${ }^{3}$ The effect of two of these factors, parity and age, is shown in tables 5 and 6.

In both communities death with associated congenital abnormality is closely related to social class. Social class specific mortality rates, however, show that the Asian population has excessive rates of death associated with congenital abnormality when compared with similar social class groups in the non-Asian population. As recent studies have suggested that periconceptual vitamin status could be concerned in the genesis of neural tube defects, ${ }^{5}$ this might be particularly important in the Asian population. Consanguinity might influence levels of abnormality. In 1981 midwives in Bradford analysed marriages and found that $48 \%$ of Pakistani marriages were between first cousins compared with $8 \%$ of Indian marriages and $0.5 \%$ of non-Asians. In addition the generally higher parity of Asian mothers and their practice of child bearing till late in life may have a bearing on the incidence of congenital abnormality.

It seems unlikely that the social class structure of the Asian population will change in the immediate future, and the reduction of high levels of mortality and morbidity will depend on the use of simple intervention measures, such as vitamin supplementation of the Asian mother during pregnancy. Asian families should know that genetic screening and counselling are readily available. In a London based study $60 \%$ of Asian families at risk requested antenatal diagnosis for thalassaemia. ${ }^{6} \mathrm{This}$ interest may extend to termination of affected

Table 4 Death rates by social class

\begin{tabular}{|c|c|c|c|c|}
\hline \multicolumn{2}{|c|}{ Rate per total 1000 births } & \multicolumn{3}{|c|}{ (Stillbirths and infant deaths 1979-81) } \\
\hline \multirow[b]{2}{*}{ Social class } & \multicolumn{2}{|l|}{ Asian } & \multicolumn{2}{|l|}{ Non-Asian } \\
\hline & $\begin{array}{l}\text { Deaths associated with } \\
\text { congenital abnormality }\end{array}$ & Other deaths & $\begin{array}{l}\text { Deaths associated with } \\
\text { congenital abnormality }\end{array}$ & Other deaths \\
\hline $\begin{array}{l}\text { I and II } \\
\text { III } \\
\text { IV and V }\end{array}$ & $\begin{array}{c}- \\
14 \cdot 1 \\
20 \cdot 0\end{array}$ & $\begin{array}{r}7 \cdot 2 \\
16 \cdot 3 \\
23 \cdot 2\end{array}$ & $\begin{array}{r}3 \cdot 6 \\
3 \cdot 7 \\
10.6\end{array}$ & $\begin{array}{r}5 \cdot 9 \\
11 \cdot 0 \\
24 \cdot 3\end{array}$ \\
\hline
\end{tabular}

Table 5 Bradford health authority: parity specific stillbirth and infant mortality $1975-81$ inclusive

\begin{tabular}{|c|c|c|c|c|c|c|}
\hline \multirow[b]{2}{*}{ Parity } & \multicolumn{3}{|l|}{ Non-Asian } & \multicolumn{3}{|l|}{ Asian } \\
\hline & $\begin{array}{l}\text { Stillbirths and } \\
\text { deaths }\end{array}$ & Births & Mortality rate & $\begin{array}{l}\text { Stillbirths and } \\
\text { deaths }\end{array}$ & Births & Mortality rate \\
\hline $\begin{array}{l}0 \\
1,2,3 \\
4,5,6 \\
\geqslant 7 \\
\text { Not known }\end{array}$ & $\begin{array}{r}263 \\
307 \\
35 \\
2 \\
3\end{array}$ & $\begin{array}{r}11896 \\
15284 \\
771 \\
61 \\
9\end{array}$ & $\begin{array}{l}22 \cdot 1 \\
20 \cdot 1 \\
45 \cdot 4 \\
32 \cdot 8\end{array}$ & $\begin{array}{r}101 \\
180 \\
75 \\
30 \\
3\end{array}$ & $\begin{array}{r}2631 \\
5 \cdot 726 \\
1943 \\
483 \\
5\end{array}$ & $\begin{array}{l}38 \cdot 4 \\
31 \cdot 4 \\
38 \cdot 6 \\
62 \cdot 1\end{array}$ \\
\hline Total & 610 & 28021 & $21 \cdot 8$ & 389 & 10788 & $36 \cdot 1$ \\
\hline
\end{tabular}

Table 6 Bradford health authority: age specific stillbirth and infant mortality 1975-81 inclusive

\begin{tabular}{|c|c|c|c|c|c|c|}
\hline \multirow[b]{2}{*}{ Age (y) } & \multicolumn{3}{|l|}{ Non-Asian } & \multicolumn{3}{|l|}{ Asian } \\
\hline & $\begin{array}{l}\text { Stillbirths and } \\
\text { infant deaths }\end{array}$ & Births & Mortality rate & $\begin{array}{l}\text { Stillbirths and } \\
\text { infants deaths }\end{array}$ & Births & Mortality rate \\
\hline $\begin{array}{l}<20 \\
20-35 \\
35-39 \\
\geqslant 40\end{array}$ & $\begin{array}{r}126 \\
456 \\
25 \\
3\end{array}$ & $\begin{array}{r}4143 \\
22750 \\
905 \\
223\end{array}$ & $\begin{array}{l}30 \cdot 4 \\
20 \cdot 0 \\
27 \cdot 6 \\
13 \cdot 5\end{array}$ & $\begin{array}{r}35 \\
281 \\
40 \\
33\end{array}$ & $\begin{array}{r}914 \\
8486 \\
760 \\
628\end{array}$ & $\begin{array}{l}38 \cdot 3 \\
33 \cdot 1 \\
52 \cdot 6 \\
52 \cdot 6\end{array}$ \\
\hline Total & 610 & 28021 & $21 \cdot 8$ & 389 & 10788 & $36 \cdot 1$ \\
\hline
\end{tabular}


fetuses, but such a service would have to be offered in the highest confidence.

Many non-Asian women find antenatal clinics overcrowded and impersonal, and this is likely to be worse for Asian mothers where communication difficulties are common. The greater provision of interpreters and other Asian health workers could ensure higher levels of attendance, fewer communication difficulties, and produce practical suggestions for improving antenatal facilities for Asian families.

A recent study has highlighted some of these problems of the Asian population with regard to antenatal care. ${ }^{7}$ Suggestions for improving both poor antenatal attendance and standards of antenatal care were made, but a real improvement in perinatal outcome will probably take place only when the Asian community can be helped to accept and use the existing medical facilities. This could perhaps be best achieved by concentrating resources on health education within schools.
We thank Sandra Haigh for undertaking the statistical analysis.

\section{References}

${ }^{1}$ Terry PB, Condie RG, Setatree RS. Analysis of ethnic differences in perinatal statistics. $\mathrm{Br} M e d J$ 1980; 281: 1307-8.

${ }^{2}$ Robinson MJ, Palmer SR, Avery A. Ethnic differences in perinatal mortality-a challenge. J Epidemiol Community Health 1982; 36: 22-36.

${ }^{3}$ Lumb KM, Congdon PJ, Lealman FR. A comparative review of Asian and British born maternity patients in Bradford, 1974-8. J Epidemiol Community Health 1981; 35: 106-9.

4 Office of Population Censuses and Surveys Monitor. Infant and perinatal mortality. London: OPCS, 1979: 1-12.

${ }^{5}$ Smithells RW, Ankers C, Carver ME, et al. Apparent prevention of neural tube defects by periconceptual vitamin supplementation. Arch Dis Child 1981; 56: 911-8.

- Modell B, Ward RHT, Fairweather DVI. Effect of introducing antenatal diagnosis on reproductive behaviour of families at risk for thalassaemia major. $\mathrm{Br}$ Med J 1980; 280: 1347-50.

${ }^{7}$ Clarke C, Clayton GC. Quality of obstetric care provided for Asian immigrants in Leicestershire. Br Med J 1983; 286: 621-3. 